\title{
Research and Development of Vacuum - Lined Ladle
}

\author{
Weiwu Liang*, Xiaochang Zhu, Xiaofeng Zheng, Junling Liu \\ Foundry Engineers of Zhejing Wujing Machine Manufacture CO. LTD, Wuyi, China
}

Email address:

liangweiwu168@163.com (Weiwu Liang)

${ }^{*}$ Corresponding author

\section{To cite this article:}

Weiwu Liang, Xiaochang Zhu, Xiaofeng Zheng, Junling Liu. Research and Development of Vacuum - Lined Ladle. International Journal of Industrial and Manufacturing Systems Engineering. Vol. 4, No. 1, 2019, pp. 1-5. doi: 10.11648/j.jimse.20190401.11

Received: October 18, 2018; Accepted: January 29, 2019; Published: February 25, 2019

\begin{abstract}
Due to defect of poor heat preservation property, the common steel ladles can't pour numbers of boxes by one bag for special steel, such as high manganese steel which is sensitive to casting temperature, casting grain size and mechanical properties. The common steel ladles cooling fast often cause cold ladle and misrun. For better insulation, a vacuum insulation layer was added to the ladle to maintain the temperature of the molten steel, reduce the heat absorption of molten steel by ladle and reduce heat exchange with the outside world. The test results showed that the vacuum-lined steel ladle had a desired insulation performance which was much better than ordinary ladle. It improved the properties of castings and also had distinct energy - saving effect. Its good insulation performance brought a series of advantages, such as heating up fast during preheating of ladle, pouring temperature of molten steel could be further reduced, refining the casting grain size, improving the mechanical properties of the casting and wear resistance. Good insulation performance also could extend pouring time. At the same time, the low temperature ladle wall brought good working environment to foundry workers.
\end{abstract}

Keywords: Steel Ladle, Vacuum Lined Ladle, Foundry Equipment, Cast

\section{Introduction}

Zhejiang Wujing Machine Manufacture Co., ltd. is one of the top 100 casting manufacturers in China with annual output of 35000 tons castings. Main products are mining machinery, screening machinery, and wear-resistant steel castings such as high manganese steel which includes 14000 different types of castings from $10 \mathrm{~kg}$ to $18000 \mathrm{~kg}$, and crushers for mining and quarrying industry. With the increase of output, the capacity of intermediate frequency furnaces had been upgraded, one from 3 to 5 tons and the other from 5 to 10 tons. Due to the total number of smelting furnaces per night, the number of pouring operators, bridge crane, and workplace, generally, one leaky bottom bag was used to tap all molten steel in the ladle at one time. That means, during the whole pouring process of argon blowing [1], sedation and pouring, one leaky bottom bag should pour more than ten boxes of castings of different size, and sometimes more than 20 boxes because of different chemical composition. The whole pouring process usually lasted for about 20 minutes. Because the pouring temperature [2] obviously affects casting grain size and mechanical properties $[3,4]$ of the high manganese steel, its starting pouring temperature must be below $1400^{\circ} \mathrm{C}$. By the end of pouring, the molten steel temperature fell faster which often led to defects such as cold ladle [5, 6, 7], insufficient pouring, unclear cast letters, etc. These problems had heavily affected the normal production of the workshop. Heat preservation property directly affects the control of pouring temperature. So how to improve heat preservation property $[8,9]$ of steel ladle must be taken into consideration.

In 2016, I listened to Dongxue Pu's suggestion on vacuum insulation steel ladle [10], who is researcher of Shenyang Foundry Institute. A old and idle 7 ton ladle was used to perform this experiment. Its capacity was reduced from 7 to 5 tons, the rest space was used to increase the vacuum insulation liner. All the contact places with molten steel except nozzle bricks and bottom - blow argon vent bricks was insulated by vacuum liner.

\section{Test Process of Vacuum Lined Steel Ladle}

\subsection{The Structure of Vacuum Lined Steel Ladle}

An old and idle 7 ton ladle was used to perform this 
experiment. The changed structure is shown in figure 1.

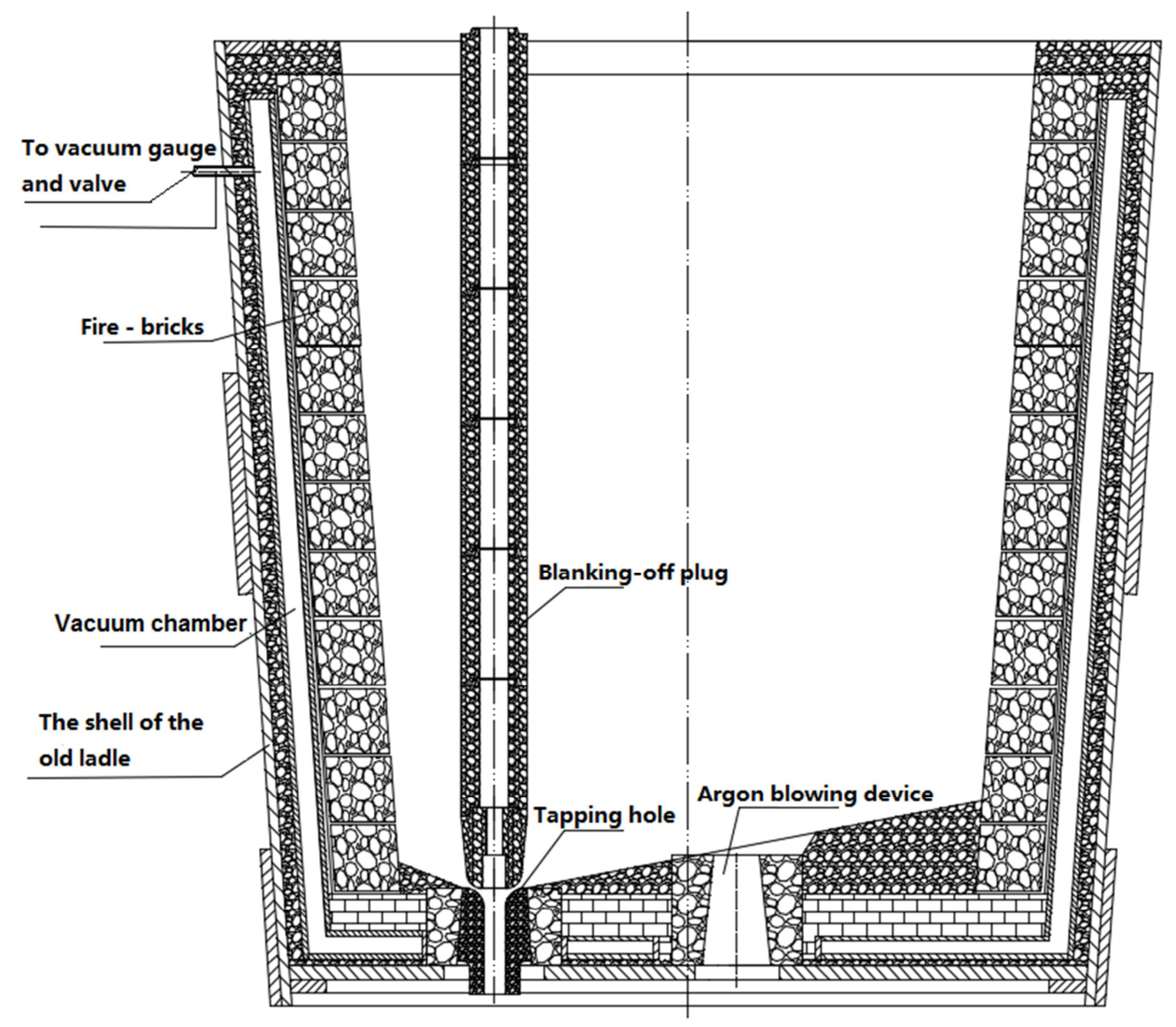

Figure 1. The structure of vacuum lined steel ladle.

\subsection{Composition of Vacuum Liner}

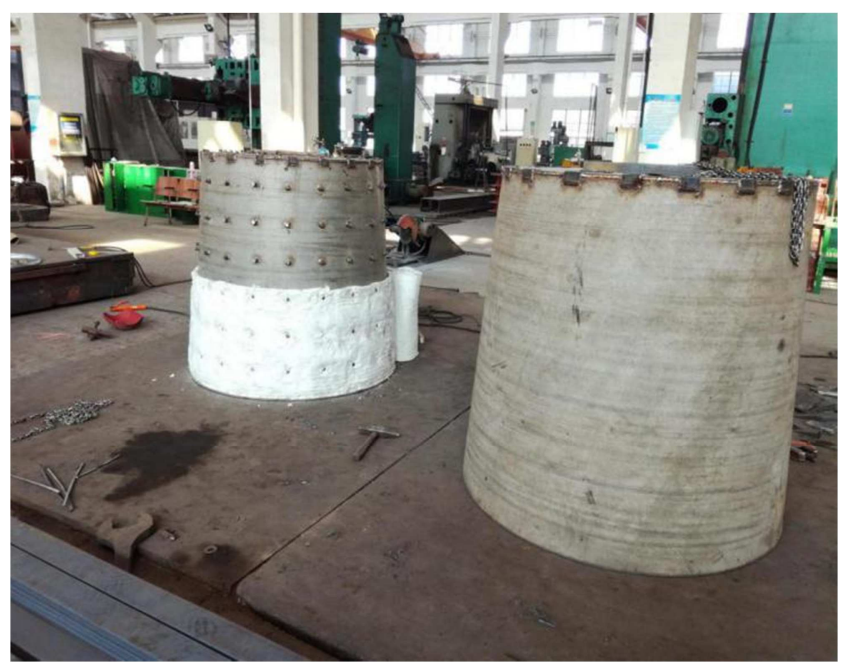

Figure 2. The inner and outer layers of vacuum liner.

Stainless steel plate was chosen to weld vacuum chamber. Considering problems such as atmospheric negative pressure, hydraulic pressure of molten steel and the thermal deformation when used at high temperature condition, some measures were taken to prevent mechanical deformation and increase heat preservation property. All welds at the force points were in flared - bevel grooves. Large curved surface were strengthened with ribs. Iron pillars had been equally spaced between the inner and outer layer to increase mechanical strength which was welded to inner layer and contact with outer layer. A thin adiabatic cloth layer was placed in the middle. Some high-temperature insulation cotton $[11,12,13]$ was also filled as a middle layer to help reduce the both problems of increasing mechanical strength and improving heat preservation property. The inner and outer layer of vacuum chamber is shown in figure 2 .

First, the inner and outer layers were welded together, performing gas leakage coating detection with high pressure gas injection and repairing weldings. Then, connecting with vacuum gauge, unidirectional valve and vacuuming the vacuum room. Finally, the vacuum sealing property had been tested in 48 hours to make sure whether it meets the requirements. The test of sealing property of vacuum room is shown in figure 3.

After passing the test of sealing property of vacuum room, it was assembled into the shell of the old ladle and the inner wall was built with fire-bricks. Attention, A high temperature insulation cloth layer was laid and a white high temperature resistant coating [14] was brushed as a insulation layer to protect the stainless steel vacuum chamber from molten steel infiltrating through the brick seam to the inner stainless layer. The insulation layer and the fire-proof wall are shown in figure 4. 


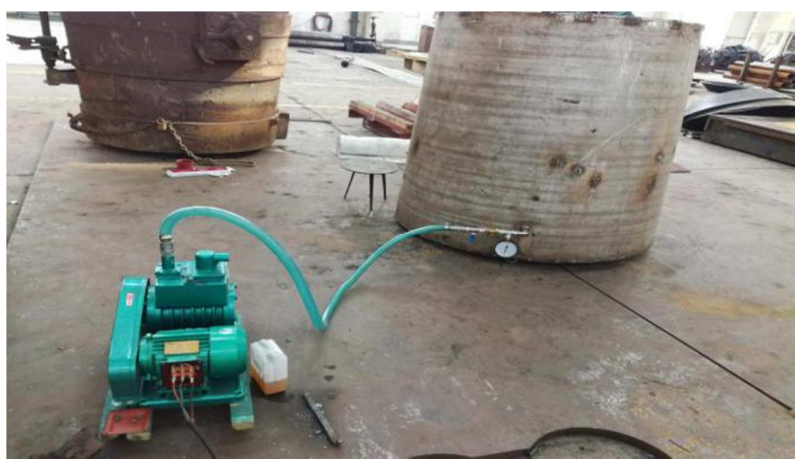

Figure 3. The test of sealing property of vacuum room.

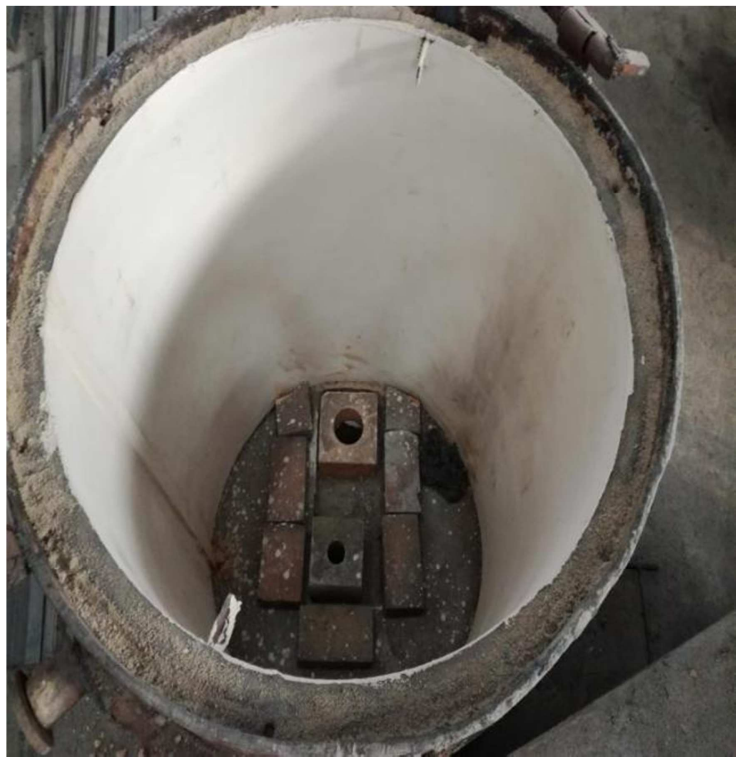

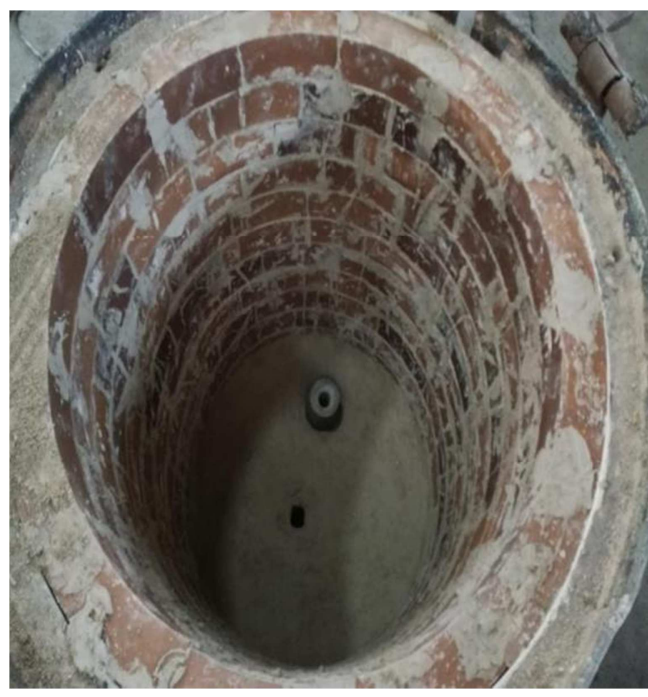

Figure 4. The insulation layer and the fire-proof wall.

\section{Results and Analysis}

\subsection{The Test of Vacuum Lined Steel Ladle}

This test was going to test 2 heats of molten steel continuously. After natural drying, the vacuum-lined steel ladle was preheated to over $700^{\circ} \mathrm{C}$ with natural gas before using. The interval smelting time of intermediate frequency furnace takes about 1 hour between two heats, so the vacuum-lined steel ladle was preheated again 30 minutes before the second heat. Multipoint temperatures were measured by infrared ray thermometer. The test data was shown in Table 1:

Table 1. Test data for vacuum - lined steel ladle.

\begin{tabular}{llllll}
\hline Shell Temp & Melting finish Temp & Temp decrease by Ar. Blowing & Pouring temp & $\begin{array}{l}\text { Melting steel in ladle } \\
\text { time }\end{array}$ & $\begin{array}{l}\text { Shell Temp. after } \\
\text { pouring }\end{array}$ \\
\hline $\begin{array}{l}\text { (1st heat) } 33^{\circ} \mathrm{C} \\
\text { (2nd heat) } 37.5^{\circ} \mathrm{C}\end{array}$ & $1611^{\circ} \mathrm{C}$ & $8.5^{\circ} \mathrm{C} / \mathrm{mins}$ & $1577^{\circ} \mathrm{C}$ & $15 \mathrm{mins}$ & $40^{\circ} \mathrm{C}$ \\
\hline
\end{tabular}

\subsection{The Test of Common Steel Ladle}

The common steel ladle was used 16 hours after the last use. This test was going to test 2 heats of molten steel continuously, too. The common steel ladle was preheated to over $700^{\circ} \mathrm{C}$ with natural gas before using. The interval smelting time of intermediate frequency furnace takes about 1 hour between two heats, so the common steel ladle was preheated again 30 minutes before the second heat. Multipoint temperatures were measured by infrared ray thermometer. The test data is shown in Table 2:

Table 2. Test data for normal ladle.

\begin{tabular}{llllll}
\hline Shell Temp & Melting finish Temp & Temp decrease by Ar. Blowing & Pouring temp & $\begin{array}{l}\text { Melting steel in } \\
\text { ladle time }\end{array}$ & $\begin{array}{l}\text { Shell Temp. after } \\
\text { pouring }\end{array}$ \\
\hline (1st heat $) 80^{\circ} \mathrm{C}$ & $1510^{\circ} \mathrm{C}$ & $11.3^{\circ} \mathrm{C} / \mathrm{min}$ & $1413^{\circ} \mathrm{C}$ & $19 \mathrm{mins}$ & $131^{\circ} \mathrm{C}$ \\
(2nd heat) $145^{\circ} \mathrm{C}$ & $1481^{\circ} \mathrm{C}$ & $13.5^{\circ} \mathrm{C} / \mathrm{min}$ & $1417^{\circ} \mathrm{C}$ & $13 \mathrm{mins}$ & $201^{\circ} \mathrm{C}$ \\
\hline
\end{tabular}

\subsection{Comparative Analysis of Vacuum Lined Steel Ladle and the Common Steel Ladle}

The ladle's insulation preservation property was verified from two aspects of the ladle shell temperature and the temperature drop of the molten steel. From the datas in the tables above, it can be seen that the shell temperature was only $41^{\circ} \mathrm{C}$ after the vacuum-lined ladle was continuously poured 2 heats, and the total temperature increase was less than $10^{\circ} \mathrm{C}$. By using the ordinary ladle, the shell temperature was increased to $201^{\circ} \mathrm{C}$ after continuously poured two heats, and the total temperature rose by $121^{\circ} \mathrm{C}$. At the same time, compared with the cooling of molten steel during argon blowing, the average cooling rate of ordinary ladle was more 
than $3^{\circ} \mathrm{C}$ per minute.

Now, suppose that the average temperature of the shell of vacuum lined ladle for continuous multi-ladle pouring all night is $50^{\circ} \mathrm{C}$, the average temperature of the shell of common ladle for continuous multi-ladle pouring all night is $220^{\circ} \mathrm{C}$, and the room temperature is $25^{\circ} \mathrm{C}$. The heats lost of different ladles from the shell (Including side and bottom) are as follows:

Vacuum ladle surface area:

$$
\mathrm{S}_{\text {vacuum ladle }} \approx 7.6 \mathrm{~m}^{2}
$$

Outer surface heat dissipation:

$$
\mathrm{Q}=\mathrm{a}(\mathrm{tw}-\mathrm{to}) \mathrm{S}
$$

Calculation result:

$$
Q_{\text {vacuum ladle }}=7600 \mathrm{w}
$$

Total heat dissipation per minute:

$$
\mathrm{q}=\mathrm{Qt}
$$

Calculation result:

$$
\begin{aligned}
& q=456000 J \\
& q=c m \Delta f
\end{aligned}
$$

For vacuum lade:

$$
\Delta \mathrm{f}=0.198^{\circ} \mathrm{C}
$$

Similarly, the total heat dissipation per minute of ordinary lade can be calculated.

For ordinary lade:

$$
\Delta \mathrm{f}=1.2^{\circ} \mathrm{C}
$$

Based on the calculation results above, for a 5 ton vacuum lined ladle, it can see that only the heat dissipation of side and bottom surface cause molten steel cooling about $0.198{ }^{\circ} \mathrm{C}$ per minute. For a 5 ton ordinary ladle, only the heat dissipation of side and bottom surface cause molten steel cooling about $1.24^{\circ} \mathrm{C}$ per minute which is 6.3 times as much as the vacuum lined ladle. If adding the heat absorption of different ladle body raised different temperatures, the temperature gap of molten steel will be further increased.

\section{Conclusions}

Due to good heat preservation property of the vacuum lined steel ladle, compared with ordinary ladles, the temperature of molten steel can be increased by $1^{\circ} \mathrm{C}$ per minute during the pouring process. Supposing that the pouring process lasts 10 minutes, at the end of pouring, molten steel in the ladle was $10^{\circ} \mathrm{C}$ higher than that in the ordinary ladle. It means the pouring time can be longer, the probability of accidents resulting in inability to pour can be greatly reduced where the plug rod had been stuck in solidification liquid steel with the decrease of temperature. It is realized that a bag of steel water can be poured more than 10 boxes of castings and meet the production requirements of the factory. At the same time, the good vacuum insulation property makes the temperature difference between the first and the end parts of castings smaller and brings high quality products. The shape, weight and mechanical properties of the castings were basically the same from the first to the last, at the end of the casting stage, the fine structure of the cast type, etc., can also be clear and full. Because of its excellent thermal insulation, it reduces the natural gas energy needed for ladle preheating and baking. Reduced the amount of work required to clean up residual molten steel solidified in the ladle.

And when multiple ladles are poured continuously, the low temperature outer wall of ladle brings a good operating environment to the workers who pouring and replacing the nozzle.

In conclusion, the ladle with vacuum insulation, as long as it can be checked in time before use every day, and vacuum pump can guarantee the high vacuum degree, can realize all kinds of benefits in the production and use above. For steel that requires argon blowing refining in the ladle [15] and sedation for more than 8 minutes to begin pouring, the effect of heat preservation and prevention of freezing of the bottom nozzle is particularly evident. It is worth popularizing in large and medium steel pouring ladle.

\section{References}

[1] Jianhua Liu, Jie Zhang \& Kangwei Li, "Current situation and Development trend of Bubble removal Technology" [J]. Steelmaking, No. 2, pp. 1-9. 2017.

[2] Dongxue PU, Xianzhong Ping \& Feng Qiao, “Technological measures for refining the microstructure of wear resistant castings" [J]. Wear resistant Materials and Castings in China, No. 14, 2016.

[3] Jingpei Xie \& Wenyan Wang, "Wear-resisting austenitic manganese steel" [M], Science Press, Beijing, 2008.

[4] Zengzhi Zhang, "wear-resistant high manganese steel" [M]. Metallurgical Industry Press, Beijing, 2002.

[5] Zhanzeng Liu \& Hongzhi Guo, "Development and present situation of heat transfer research in ladle" [A], Iron and Steel Research, vol. 35 no. 1. p59, 2007.

[6] Shouxin Tian, Guangzhen Gao \& Defeng Li, "Study on reducing heat loss in ladle" $[\mathrm{J}]$, Refractory, no. 1, pp 51-53, 2016.

[7] Zhongjiang Liu \& Bo Song, “ Energy Saving liner of Ladle” $[\mathrm{J}]$. Proceedings of the 15 th National Conference on steelmaking, 2010.

[8] Yifeng Chen, Guozhang Jiang \& Gongfa Li, "Influence of new ladle heat preservation and energy saving liner on ladle temperature and thermal insulation performance" $[\mathrm{J}]$, Mechanical Science and Technology, no. 11, pp 82-86, 2012. 
[9] Shaoqin Liu, Xiaoli Xi \& Wang Shaohua, "ladle heat preservation technology" [J], World of Metals, no. 1, pp 3434, 2012.

[10] Jianan Zhou \& Jianbo Xie, "New vacuum shell ladle R \& D" [A], Iron and Steel, Vol. 33, No. 2, pp 38-42, 2017.

[11] Changjiang Jia \& Dejing Song, "A study on the Application of New Heat Insulation material for casting Ladle", Foundry equipment and Technology, no. 2, pp 42-44, 2016.

[12] Guishun Li, “Application Research of New Insulation material in Ladle Insulation layer" [J], Metallurgical Journal, sum. 198 no. 2. April 2012.

[13] Ze Wei \& Xueqi Liu, "Application and Exploration of Energysaving Technology for Heat Insulation Refractory in Ladle" wide and thick Plate, no. 3, pp 36-38, 2017.

[14] "Latest research on refractory and high temperature resistant coatings for ladle" [Z], Beijing. Zhisheng Weihua chemical co., Ltd. 2012.
[15] Wu Hua, "Research on the Heat Insulation Technology of 150t Converter Ladle" [J], The Wind of Science and Technology, issue $09,2017$.

\section{Biography}

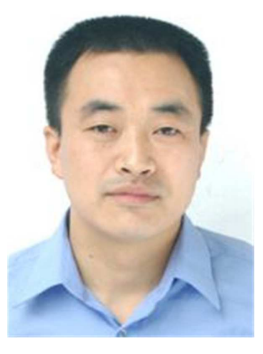

Weiwu Liang, male, was born in 1973 in

Wu-yi, China, mainly engaged in casting process design work, foundry engineer of Zhejing Wujing Machine Manufacture CO. LTD. He is also a member of the National Commission for Standardization of Casting Technology on Wear Resistant Materials and Castings. He has many foundry invention patents, his papers have been published in the national core periodical, such as "the casting with taper deep long hole anvil" and so on. 